\title{
Blindness is Non-Barrier to Employability in Nigeria
}

\author{
Mary M. Aiyeleso \\ Department of Special Education and Rehabilitation Sciences, Faculty of Education \\ University of Jos, Jos Nigeria
}

\section{Doi:10.5901/ajis.2016.v5n3p135}

\begin{abstract}
This paper examined blindness is non-barrier to employability in Nigeria. It identified general concepts of blindness. The cultural and scientific causes of blindness were also identified. Wrong assumptions towards the employment of the persons who are blind were addressed. Types of job opportunities for persons who are blind in Nigeria and job opportunities for the blind in advanced countries were also discussed. The paper also identified attitudes of employers towards the employment of the blind. Useful recommendations on how best employment opportunities would have a breakthrough for persons with blindness were also profound.
\end{abstract}

Keywords: blindness, low vision, partially sighted, visually impaired, employment.

\section{Introduction}

In the early days when formal education of the blind/visually impaired was quite unheard of in Nigeria, most persons with blindness were seen roaming the streets, visiting houses, market places and public places like mosques, and churches begging for alms by singing and dancing. There were quite a number of them that were musicians who went about entertaining people with their songs at public gatherings and market places. By so doing, they were always compensated for their performances either in kind or in cash.

Most female persons who are blind were mostly kept at homes and were taught some domestic works such as cooking and washing which would enable them run their own homes when eventually they got married. When formal education of the blind in Nigeria was introduced by the missionaries in 1953, the primary aim was to teach the blind how to Braille, so that they would be able to read the Bible for themselves. They were also taught simple craft and farming so that after leaving the school or centre for the blind, they might be able to earn their own living. During these olden days parents of the individuals with blindness were not enlightened on the job opportunities for their children so as to know the importance of sending their wards to schools. Employment is important because work takes up a greater portion of our time daily. By working, such a person will not be idle, the individual is brought into contact with activities, ideas, organizations and people of all works of life. He will not only be useful to himself or family, but also to the society as well. Therefore, work is seen as using one's physical or mental energy to accomplish something productive. That is the reason why Durodola (2004) stressed that "Besides providing for economic support, work offers opportunity for social interactions, a chance to use and further enhance skills in one's line of work. Thus, work generates the respect of others and more importantly, one can be a source of pride and satisfaction.

The blind persons' jobs should not be an exceptional. They have just as much right to education and employment as their sighted and normal counterparts. Many occupations do not require complete physical fitness, but effective capabilities of the existing functioning ability. The visually impaired can also fit suitably into the various employment agencies that are available depending on their degree of impairment. School learning programmes combined with parental involvement can do much to prepare young people visually impaired for work and for life in the community.

In Nigeria and other developing countries in Africa, opportunities for employment of visually impaired young persons are quite limited. This is because of the adverse economic situation and lack of employment opportunity for the handicapped. Algahim (2002) observed that despite the great efforts made in many countries towards special education and vocational rehabilitation field, employment opportunity for the visually impaired especially in developing countries are still rare. Furthermore, the under expectation and stereo-type attitudes about the limitation that are imposed on the blind persons made it difficult for them to get jobs. Yuker (2006) also noted that in many under-developed and developing countries in the world, both the governments and the generality of people are not investing in the handicapped human resources. Their argument was that, a large proportion of their people who are illiterates but not handicapped must first 
be trained to secure gainful employment before attention can be given to the handicapped who unfortunately regarded as people who cannot hold competitive employment even with the best of the training in the world. This explains why the writer is emphasizing that blindness should not be a barrier to the employment of the affected person in Nigeria and developing country contrary to the negative notion held in these societies. It is again rather unfortunate and a loss of human power and resource inspite of the numerous opportunities that exist in Nigeria and some societies where the persons who are blind might find themselves, they are often not consider employable while their sighted counterparts are often given the upper hand because of the society's negative attitudes towards the affected individuals.

Furthermore, because of the failure of the society and professionals to go into the field and actually find out for themselves the capabilities of the visually impaired/blind in performing certain jobs have made people to see the blind persons not as competent enough to carry out most of the jobs available in the employment market. The writer is of the view that previously the attitude of the Federal and State Government to the welfare of the persons who are blind in terms of providing employment opportunities leaves much to be desired. But with the declaration of the year 1981 as the International Year of the Disabled, and with the growing awareness of the importance of integrating the disabled into the active social and economic life of the society in which they live, then adequate support and provision of jobs for persons who are blind will be consider a necessity.

In order to encourage the individuals who are blind to live an independent life, the wrong assumption held about their employment potentials should be avoided. This paper therefore, will focus on blindness is non-barrier to the employment of persons with blindness. Useful recommendations will be made on how they could be better helped by the government and society to get gainful employment in order for them to be tax payers, not tax eaters by contributing to the economic development of the nation will be presented.

\section{General Concept of Blindness}

Blindness is an impairment in vision that even with correction still adversely affects a child's educational performance. Harell (2000) defined blindness as visual acuity for distance vision of 20/200 or less in the better eye, with best correction. Low vision refers to visual acuity greater than 20/200 but not greater than 20/70 in the better eye after correction. Thus, a blind person can see at a distance up to 20 feet after visual correction what a person with normal visual vision can see at 200 feet. Similarly, the partially sighted are capable of seeing at 20 feet what a person with normal eyes can see at seventy feet. Mba (1995) also described vision as a vital factor in the development, progress and wellbeing of children and young people. Similarly, Ozoji (2003) defined visually impaired as children whose the sense of vision is defective and this could range from ability to see a little to total blindness. The importance of vision calls for understanding of the plight of visual impairment and its implication for the general development of the child who is visually impaired or blind.

This is because; visual perception is one of the main sources through which humans senses understand the world around them. It is through the visual sense that a large proportion of human information processes takes place. Yet, a number of people have this visual impairment either severely or profoundly. When an individual is visually impaired, his learning, social interaction, general operation and adjustment are bound to be adversely affected.

\section{Cultural Causes of Blindness}

In some Nigerian cultural societies, it is believed that when a pregnant woman goes to fetch water at a stream in the night, she will give birth to an abnormal or disabled child. In other words, the deity or gods of the river or stream have made the child blind from the womb as a punishment to the affected mother to serve as a correction and lesson to other pregnant women who would like to do same when they are pregnant. In some other communities in Nigeria, a pregnant woman is prohibited from eating certain foods, but if she violates such rules or taboo, the result or consequence could be that the birth of the so-called abnormal child. In other cultures in Nigeria it is a taboo for a pregnant woman to stay out late at night. But if she persists in violating this taboo, she may one day jam or come across an evil spirit and the consequence will be that the baby in her womb will become handicapped, usually struct with blindness or other forms of disabilities. This is just to mention but few.

\section{Scientific Causes of Blindness}

According to Okeke (2001) Blindness is caused by various diseases, and these diseases could be rubella, syphilis, 
gonorrhoea some of which are infectious. Other diseases that affect vision include cataracts of all kinds, disorders of the optic nerve and the conjunctive. Atrophy is the commonest form of optic nerve disorder that affects visual organ.

Other general diseases that affect vision include measles, meningitis, scarlet fever, epilepsy, hydrocephaly, multiple scelerosis and brain tumours. Accidents caused by explosions or firearms, substances in the eye, alcoholic poisoning, tobacco, chronic lead and occupational hazards. Most deadly diseases like small pox, German measles when they affect a pregnant woman during the first three months of pregnancy may lead to congenital blindness.

\section{Wrong Assumptions about Employment of the Blind}

The society at large often regards the blind as second class citizens who cannot do any job to earn a living other than to beg or sing for alms in the streets. So employers of labours also assume that the persons who are blind are incapable of performing certain tasks even though they are trained to do so. At times when there are vacancies in establishments, a sighted person is given preference over and above the blind/visually impaired. The wrong erroneous assumption is that a normal sighted person can perform more efficiently in any given work than a person who is blind. The above instances reflect the attitude of many employers towards the blind. But the fact is that a qualified blind/visually impaired in any field can equally perform well or even better than the sighted in that field. Consequently, if given the employment opportunity, persons with blindness can adjust to their disability and many cases can produce more effectively or better than sighted persons in any given task/work. In Nigeria at present, there are many blind persons who are musicians, doctors, lecturers, telephone operators, secretaries and in many other fields of work just to mention a few. This is the reason why Tail (2000) stated that "An employed blind person can contribute to the progress of the society which can make him/her obtain real equality". This means when a blind person secures a job, he becomes a dignified human being and is assured of economic independence.

\section{Types of Job Opportunity for Persons with Blindness}

It is a right for every qualified Nigerian to secure a job of his choice after completing his studies. Job opportunity in its real sense is the ability to secure a piece of work for which you are paid. There are different types of jobs in Nigeria, and the persons with blindness can efficiently cope with most of them, yet, the stigma 'blind' has prevented many of them from actually doing what they had wanted to, due to the negative attitudes of the employers and the society at large. The government itself have not shown much concern to the employment of the visually impaired in different arms of organization or establishment in Nigeria. The fact is that this group of affected individuals can be employed for specific jobs for which they are qualified. The common occupations in which many persons who are blind are employed in the developing countries according to Amwe (1995) include: switch boards operation, vending stand operation, teaching, packaging and assembling work, bamboo and wicker work, shoe and brush making, sewing, knitting, leather work, crafts, laundry work, fishing, baking and confectionary.

In actual sense, the government had tried to make the blind/visually impaired self- employed by giving them loans to enable them establish a small scale business in order that they too can get along with their normal sighted colleagues. But the fact is that not many blind are able to access the loan because of the stringent condition attached to it. This means without being self-employed or given job opportunities, they are taken back to square one as majority of them still roam the street seeking for daily bread by begging for alms or doing degrading menial jobs. Again, if there are no or low patronage of their small scale businesses, they resort to finding solace in street begging. This in turn, makes the training and education acquired worthless thus rendering them unproductive and useless in the society.

\section{Job Opportunities for the Blind in Advanced Countries}

In most advanced countries of the world today like Britain and America, no blind person of normal intelligence will grow up without formal school education and even some vocational training. Because of this, Umeh (1998) explained that some programmed texts modified for audio presentation to the blind have been developed. However, many blind persons are unable to obtain employment that is appropriate to their capacities.

This is the reason why Warren (2000) explained that one major decision of the Oxford Conference in 1999 was that blind children should be given full opportunities for general and vocational education in school adequately equipped for the education of the blind and with qualified teachers, and that the national education system should ensure that all blind children are given education according to their interest and aptitudes at least equal to that which they would have 
received and had not.

Ronald (1999) in East Malaysia explained that why it is also necessary to consider the job possibility for the blind after the education and training have been completed is because experience has shown that both in Asia and Africa, persons who are blind can in fact at a much lower cost of training, fulfil useful roles such as village farmers and craftsmen. Thus, the blind can be integrated into the village community and family life in almost the same way as the sighted. Ronald further urged the East Malaysians not to lose sight of the important part to be played by the trained visually impaired/blind persons in professions, open industry and general open employment where they are already resident town dwellers".

Furthermore, the American Foundation for the Blind 1999 compiled a list of occupations occupied by blind persons in USA and Canada which include: sales and managerial work, clerical, professional and technical occupations.

\section{Attitudes of Employers Towards the Employment of Persons with Blindness}

Most of employers both in private and public organisations in this country have often shown negative attitudes towards the employment of the blind. The wrong assumptions which exist in private organizations as confirmed by the writer is that they prefer employing normal sighted persons to blind persons who cannot see the production equipments or materials much more handle them perfectly or efficiently. The negative conclusion of the employers is that those who are blind cannot cope with the intensive competitive factory/company's work ethics expected by the managers. For this reasons the blind are thus denied employment in order to avoid inefficient and low productivity which can result in poor sales.

Employers often regard persons with blindness as those who cannot get to their places of work on time and that their handicapping condition may hinder them from performing most functions. But in the actual sense the blind can get to their offices in good time and with few days mobility orientation they can get to all places within their work areas. Employers only need to give proper orientation to the blind/visually impaired in order to help them carry out their functions effectively in their places of work.

The wrong assumptions of the employers of labour is that even if a blind person has the same qualification as a sighted counterpart, there is a possibility that the sighted person will perform better than the blind person in every aspect of work both applied for. But, this assumption is yet to be empirically proven. Beside in most in cases, those who are blind have proven to be more intelligent than normal sighted person. The implication of this is that the employers and the society at large should stop or avoid paying attention to the disability of persons who are blind; they should focus on these individuals' ability and potentials because there is ability in disability.

\section{Conclusion}

It can be concluded that the problems of job opportunities for persons who are blind lie with the government and the negative attitude of the society towards them. The government has not categorically spelt out that individuals who are blind should be given certain jobs/employment that exists in the different ministries and parastatals.

The government has only tried to create few sheltered workshops in which only few and lucky blind/visually impaired are given some employment. Therefore, from the foregoing, it is suggested that the government of Nigeria should help create more job opportunities in different ministry to absorb persons with blindness. The general public should be made to understand that those who are blind can perform equally as well as their sighted counterparts if given the employment, training and chance to do so.

\section{Recommendations}

Based on the above facts, the following recommendations were made: The three tiers governments should organize employment awareness training seminars for the private and government employers on the potentials and contributions that the blind person can make to nation development at private and public sectors. This will help create employment opportunity for the blind/visually impaired.

Persons with blindness should be given vocational and rehabilitation education by specialized teachers and be provided with the right equipment and materials. They also need the services of social workers and job placement officers in their schools or vocational centre who would study the different types of jobs available and direct them to the one most suitable for their abilities. Furthermore, follow-up services by the job placement officer to the persons with blindness 
places of work is necessary, this will encourage them to always put in their best in any establishment they are employed, proving wrong the negative attitude of the society towards them. The affected persons also need effective mobility/orientation training so that the few lucky ones who are given job opportunities would be able to get to their work places on time, and be conversant with the positions of the sophisticated equipment within their places of work.

The government should have a definite policy which will help the blind/visually handicapped individual secured employment immediately after graduation. They should also establish more rehabilitation centres which will be capable of employing all the visually handicapped persons according to their areas of specialization.

\section{References}

Algahim, B.A. (2002). Teaching the visually handicapped. Ibadan: University Press.

Amwe, D.O. (1995). Issues on Special Education and Rehabilitation of the disabled. Jos: Department of Special Education, University of Jos.

Durodola, M.T. (2004). Handbook on vocational rehabilitation. Ibadan: Yomi Press.

Harell, F. (2000). Principle and practice of education of the blind. Tokyo: University press

Mba, P.O (1995). Fundamentals of special education and vocational rehabilitation. Ibadan Codat Publications.

Okeke B.A (2001). Essentials of special education. Nsukka: Afro-orbis publications Itd.

Ozoji D.E. (2003). Special education for beginner professionals Jos: Deka Publications.

Ronald, A. (1999). The exceptional child in the family. New York: Stralton coy.

Tail, L.S. (2006). Employment opportunities for the blind. London: Chapman Coy.

Umeh, T. (1998). Vocational Rehabilitation of the exceptional children. Asia: University Press.

Warren, D.H (2000) Blindness and early childhood development (2nd ed) New Yorks: American foundation for the blind.

Yuker, H.E. (2006). Attitudes of people towards handicapped individuals. Washington: University Press. 
